Check for updates

Cite this: RSC Adv., 2020, 10, 39385

\title{
The structural composition of components contributes to the superiority of the geoherb Alisma orientale for "diuresis and diffusing dampness"
}

\author{
Ru Li, $\uparrow^{a}$ Zhi-li Li, $\uparrow^{a}$ Ya-ping Chen, $\dagger^{a}$ Wei-quan Bu, Wen-bo Ding, ${ }^{b}$ Bing Yang, ${ }^{b}$ \\ Chun-fei Wang, ${ }^{\mathrm{b}}$ Liang $\mathrm{Ma}$, ${ }^{\text {b }}$ Xiao-bin Jia*a and Liang Feng (D)*a
}

The purpose of this study is to explore the intrinsic reasons for the superiority of the salt-made geoherb Alisma orientale via comparing the content of various components of the salt-made geoherb Alisma orientale. The effects of "diuresis and diffusing dampness" using salt-made Alisma orientale from seven different origins were investigated through pharmacodynamic experiments in vivo and in vitro. The results indicated that salt-made Alisma orientale from different origins had diuretic efficacy; this was demonstrated by the significant increase in the volume of rat urine, the concentration of $\mathrm{Na}^{+}, \mathrm{K}^{+}$, and $\mathrm{Cl}^{-}$in the urine, and the significant decrease in the levels of AQP-2 in rat renal medulla and HK-2 cells. It was also revealed that the diuretic effect of salt-made Alisma orientale from Fujian Province is stronger than those from other provinces. Moreover, the main components and their proportions in the saltmade Alisma orientale samples were further analyzed via principal component analysis. The results showed that alisol A 24-acetate, alisol B, and 23-acetyl alisol B are the main components of salt-made Alisma orientale, and the optimal structural ratio of alisol A 24-acetate, alisol B, and 23-acetyl alisol B was found to be $5.38: 14.34: 11.31$ via optimizing the ratios of the three main components. It is worth noting that the optimal ratio of the three main components after optimization is the closest to the ratio of the three main components in salt-made Alisma orientale from Fujian Province. This paper reveals the "mystery" of the content ratio of the main active components and its effect on the efficacy, and showed that the proportional relationship between the content of multiple components is the key to their interactions. Therefore, this method of evaluating the quality of salt-made Alisma orientale is obviously reliable, and this study lays the foundations for quality evaluation of salt-made Alisma orientale and other herb slices.

Received 16th October 2019

Accepted 29th September 2020

DOI: $10.1039 / c 9 r a 08469 j$

rsc.li/rsc-advances

\section{Introduction}

As a traditional medicine in China, Chinese herbal slice has always been used to improve the health of our people. The quality of the herbal slice is the basis of ensuring the safety and effectiveness of traditional Chinese medicine. The quality evaluation of traditional Chinese herbal slice is still mainly based on the traditional method, the content of single or several components as the evaluation index. However, multicomponent characteristics of traditional Chinese medicine have shown that the content of single or several components does not really represent the true quality and the true clinical

${ }^{a}$ School of Traditional Chinese Pharmacy, China Pharmaceutical University, Nanjing 211198, P.R.China.E-mail:wenmoxiushi@163.com; jiaxiaobin2015@163.com

${ }^{b}$ Affiliated Hospital of Integrated Traditional Chinese and Western Medicine, Third Clinical Medical College, Nanjing University of Chinese Medicine, Nanjing, Jiangsu, 210028, P.R. China. E-mail: liangyu84@163.com

$\dagger \mathrm{Ru}$ Li, Zhi-li Li, and Ya-ping Chen contributed equally to this work. efficacy of the herbal slice. ${ }^{\mathbf{1 , 2}}$ Therefore, a method for quality evaluation of herbal slices needs to be developed urgently. ${ }^{3,4}$ In recent years, multi-dimensional chemical evaluation with statistical analysis and fingerprint analysis have been used to control the quality of herbal slices from a holistic perspective., ${ }^{5,6}$ However, these methods do not clearly explain the intrinsic reasons for the quality of the herbal slice. Our research group believes that the main property that effects the quality of a Chinese herbal slice is not the content of one or several components, but the specific proportional relationship of certain components within the herbal slice.

Alisma orientale is a dried rhizoma of Alisma orientalis (sam.) Juzep., a perennial swamp herb of Alismataceae, which "promotes diuresis and eliminates dampness". ${ }^{7-11}$ At present, Alisma orientale is mainly used for the treatment of dysuria, water swelling, diarrhea, scanty urine, heat stranguria, astringent pain and other diseases in China, ${ }^{\mathbf{1 2 - 1 7}}$ and is mainly produced in Fujian, Jiangxi, Sichuan and other provinces and is 
divided into Jian Alisma orientale and Chuan Alisma orientale. It is generally believed that Fujian produces the best quality Alisma orientale, and the efficacy of the Jianzexie is better than that obtained from other areas, however, the relationship between the producing area and its pharmacodynamics has always been an unsolved mystery.

The multi-components characteristics of traditional Chinese medicines indicate that the efficacy of traditional Chinese medicine does not depend on the content of a certain component, but on the interaction of multiple components. Our research group believes that the proportional relationship between the content of multiple components is the key to affecting their interaction, and the advantages of Fujian Alisma orientale may be related to its unique proportional relationship between multiple components.

This paper compares the effect of "diuretic and dampness" in salt-made Alisma orientale from different producing origins and clarifies its efficacy and simple mechanism, the content of the active components in Alisma orientale was analyzed, as well as its proportional relationship, and this revealed the relationship between the content ratio of the main active ingredients in Alisma orientale and its efficacy.

This study lays the foundations for evaluation of the quality of salt-made Alisma orientale and other herb slices.

\section{Experimental}

\subsection{Chemicals and materials}

Furosemide tablets were purchased from Jiangsu Yabang Pharmaceutical Co., Ltd. (Jiangsu, China), a sodium ion detection kit, potassium ion detection kit and chloride ion detection kit were purchased from Nanjing Jiancheng Bioengineering Institute, Ltd. (Nanjing, China). The Total Protein Extraction Kit, Bradford protein content test kit, $5 \times$ SDS-PAGE protein loading buffer, SDS-PAGE gel preparation kit, molecular weight of pre-dyed protein, AQP-2 antibody, EliVision plus kit, and DAB Kit were purchased from Fuzhou Maixin Biotechnology Co., Ltd. (Fuzhou, China). The ECL Test Kit, internal reference primary antibody (Rabbit $\beta$-actin), secondary antibodies (goat antimouse IgG) and secondary antibodies (rabbit anti-sheep IgG) were purchased from Nanjing KeyGEN Biotechnology Development Co., Ltd. (Nanjing, China).

Standard material alisol A 24-acetate, alisol B and alisol B 23acetate were supplied by China Food and Drug Administration (purity greater than 98\%). Acetonitrile was purchased from
TEDIA (USA, HPLC-grade). Prepared herbal medicine in small pieces ready for decoction (salt-made Alisma orientale) was collected from various companies in different provinces (Table 1) and identified as Alisma orientalis (sam.) Juzep. by Dr Long Wang from the Department of Traditional Chinese Medicine Resources, at China Pharmaceutical University.

\subsection{Preparation of Alisma orientale extract}

Salt-made Alisma orientale ( $2 \mathrm{~kg}$ ) from each origin was weighed, boiled and extracted twice with 10 times $80 \%$ ethanol (v/v) for $30 \mathrm{~min}$. The extracts were combined and freeze-dried into a powder and stored at the School of Traditional Chinese Pharmacy, China Pharmaceutical University for further application (batch number: 20180103).

\subsection{Animal experiments}

Eighty female SD rats (weighing $200 \pm 20 \mathrm{~g}$ ) were purchased from Shanghai SLAC Animal Center with certificate number SCXK (Shanghai). All the rats were kept in cages in the animal experimental center of the China Pharmaceutical University. After one week of adaptive feeding, these rats were intragastrically administrated with distilled water twice a day for $3 \mathrm{~h}$, and the gastric perfusion volume was $20 \mathrm{~mL} \mathrm{~kg}^{-1}$. After $3 \mathrm{~d}$ of continuous gavage, the drug was administered after $30 \mathrm{~min}$ for the last gavage. ${ }^{18-20}$ These model rats were randomly divided into: the model group (distilled water $20 \mathrm{~mL} \mathrm{~kg}^{-1}$ ); the furosemide positive control group (20 $\mathrm{mg} \mathrm{kg}^{-1}$ ) and salted Alisma orientale groups including Fujian, Sichuan, Jiangxi, Hebei, Hubei, Guangxi, and Henan (the extract of the high dose was equivalent to $4.0 \mathrm{~g} \mathrm{~kg}^{-1}$ of the crude drug and the low dose was equivalent to $0.9 \mathrm{~g} \mathrm{~kg}^{-1}$ relative to the crude drug). All animal procedures were performed in accordance with the guidelines approved by the Experimental Animal Research Committee of China Pharmaceutical University and approved by the Animal Ethics Committee of China Pharmaceutical University.

\subsection{Detection of biochemical indexes in rat urine}

The urine from the rats was collected using metabolic cages for $24 \mathrm{~h}$, and the volume of urine was measured accurately. The content of $\mathrm{Na}^{+}, \mathrm{K}^{+}$and $\mathrm{Cl}^{-}$in the urine was detected according to manufacturer's protocols.

Table 1 Information about salt-made Alisma orientale from each production area

Origin

Fujian Province

Sichuan Province

Jiangxi Province

Guangxi Province

Hubei Province

Henan Province

Hebei Province
Company

Anhui Jingquan Group Chinese Herbal Medicine Co., Ltd Chengdu Zhongchuan Pharmaceutical Co., Ltd

Jiangxi Heye Zexie Kunshan Sales Co., Ltd Zhejiang Yingte Chinese Herbal Pieces Co., Ltd Hubei Yuancheng Saichuang Technology Co., Ltd Nanyang Zhang Zhongjing Chinese Herbal Medicine Development Co., Ltd Hebei Dongsheng Yinghua Pharmaceutical Co., Ltd 


\subsection{Cell cultures and extract treatment}

Human renal tubular epithelial cell line (HK-2) cells were supplied by Nanjing KeyGEN Biotechnology Development. Dulbecco's modified Eagle medium (DMEM) medium containing $10 \%$ fetal bovine serum was used as the cell culture medium, and the cells were cultured in a sterile cell incubator with $5 \% \mathrm{CO}_{2}$ at $37{ }^{\circ} \mathrm{C}$. $\mathrm{HK}-2$ cells in logarithmic growth phase were seeded in a 6-well plate at a density of $1 \times 10^{7}$ cells/well and then treated using extracts of $1.6 \times 10^{-2}, 8 \times 10^{-3}, 4 \times$ $10^{-4}, 2 \times 10^{-4}, 1 \times 10^{-4}, 5 \times 10^{-5}, 2.5 \times 10^{-5}, 1.25 \times 10^{-5}$, and $6.25 \times 10^{-6} \mathrm{~g} \mathrm{~mL}^{-1}$ in DMEM high sugar F12 incomplete culture medium.

\subsection{MTT assays for cell viability}

HK-2 cells in the logarithmic growth phase were seeded in a 96well plate at a density of $1 \times 10^{5}$ cells per well and placed in a $37{ }^{\circ} \mathrm{C}, 5 \% \mathrm{CO}_{2}$ incubator for $24 \mathrm{~h}$. These cells were exposed to different concentrations of the extract of Fujian salt-made Alisma orientale for $24 \mathrm{~h}$. Sequentially, $10 \mu \mathrm{L}$ of MTT solution $\left(5 \mathrm{mg} \mathrm{mL}{ }^{-1}\right)$ was added to each well and they were incubated for another $4 \mathrm{~h}$. The medium was then removed and $100 \mu \mathrm{L}$ of dimethyl sulfoxide (DMSO) was added into each well to dissolve the formazan. After shaking at $37^{\circ} \mathrm{C}$ for $10 \mathrm{~min}$ the absorbance value of each well was measured using a full-automatic microplate reader. The percentage cell viability was calculated using the following formula, in which OD is the optical density: cell viability $(\%)=(\mathrm{OD}$ value of compound group/OD value of the control group) $\times 100 \%$.

\subsection{Western blotting}

The kidney tissues of the rats or the cells were made into a homogenate with $200 \mu \mathrm{L}$ of ice pre-cooling cracking buffer and were kept in an ice-bath for $30 \mathrm{~min}$, vortexed and fully lysed. The supernatant was collected after being centrifuged at $13000 \mathrm{rpm}$ for $10 \mathrm{~min}$ at $4{ }^{\circ} \mathrm{C}$, and the protein concentration was determined using the Bradford method. After denaturation of the protein, an equal amount of total protein was separated using $10 \%$ sodium dodecyl sulfate-polyacrylamide gel electrophoresis (SDS-PAGE), and then transferred to the membrane and blocked in $5 \%$ skim milk powder solution ( $4{ }^{\circ} \mathrm{C}$, overnight). The blocking solution and the appropriate amount of primary antibody $(1: 1000)$ were added in a shaker at $0.1 \mathrm{~mL} \mathrm{~cm}^{-2}\left(4^{\circ} \mathrm{C}\right.$, overnight). After being washed with Tween-phosphate buffered solution (TPBS) four times, a secondary antibody (diluted at $1: 5000$ ) was added and it was incubated for $2 \mathrm{~h}$ at room temperature, the membrane was then washed with TPBS four times. The developer $\left(0.1 \mathrm{~mL} \mathrm{~cm}{ }^{-2}\right)$ was added onto the NC membrane and left for $1 \mathrm{~min}$ at room temperature. The film was wrapped with plastic wrap (to avoid bubbles as much as possible). The membrane protein was quickly exposed to X-ray film in a dark room, and developed and washed in a film processor.

\subsection{High performance liquid chromatography analysis}

The extract, $0.2 \mathrm{~g}$, was dissolved in $2 \mathrm{~mL}$ of methanol, and then treated twice (30 min each time) using an ultrasound machine. The solution was filtered and centrifuged at $11000 \mathrm{rpm}$ for $10 \mathrm{~min}$. An Agilent 1100 series high performance liquid chromatograph with a quaternary pump and diode-array detector (DAD) was used for this analysis. An Alltima $\mathrm{C}_{18}(4.6 \mathrm{~mm} \times 250$ $\mathrm{mm}, 5 \mu \mathrm{m})$ column was used. The mobile phase consisted of acetonitrile-water and a gradient elution (0-5 $\mathrm{min}, 0-2 \%$ acetonitrile; 5-40 $\mathrm{min}, 2-35 \%$ acetonitrile; $40-115 \mathrm{~min}, 35-98 \%$ acetonitrile; $115-120 \mathrm{~min}, \mathbf{9 8 - 1 0 0 \%}$ acetonitrile) was used with a $1.0 \mathrm{~mL} \min ^{-1}$ flow rate. The column temperature was maintained at $25{ }^{\circ} \mathrm{C}$ and the detection wavelength was set at $210 \mathrm{~nm}$. The injection volume was maintained at $10 \mu \mathrm{L}$.

\subsection{Composition ratio of terpenoids in Alisma orientale}

The three main component terpenoids of salt-made Alisma orientale were optimized in the structural composition ratio. The specific scheme is shown in Table 2. According to the proportion of alisol A 24-acetate, alisol B and 23-acetyl alisol B in the above described optimization scheme, different media were prepared. The content ratio is the same as that shown in Table 2.

\subsection{Statistical analysis}

The high-performance liquid chromatography (HPLC) chromatograms of seven batches of Alisma orientale were imported into the Similarity Evaluation System for Chromatographic Fingerprint of Traditional Chinese Medicine (Version 2012) composed by the Chinese Pharmacopoeia Committee. The common peaks of Alisma orientale from different producing area were calculated.

The statistical data are presented as means \pm standard deviation (SD). SPSS16.0 data statistical software was used for the principal component analysis and variance analysis. The $T$ test method was used for comparison between groups. $P<0.05$ indicates that the difference has statistical significance.

Table 2 Total terpenoid component compositions ${ }^{a}$

\begin{tabular}{llr}
\hline $24 \mathrm{~A}: \mathrm{B}: 23 \mathrm{~B}$ & B $: 23 \mathrm{~B}: 24 \mathrm{~A}$ & $23 \mathrm{~B}: 24 \mathrm{~A}: \mathrm{B}$ \\
\hline$(\mathrm{I}-1) 2.99: 14.34: 11.43$ & $($ II-1) $14.34: 11.31: 11.48$ & $($ III-1) $11.31: 2.99: 14.25$ \\
$(\mathrm{I}-2) 2.99: 14.34: 8.08$ & (II-2) $14.34: 11.31: 5.38$ & $($ III-2) $11.31: 2.99: 9.06$ \\
$(\mathrm{I}-3) 2.99: 14.34: 6.01$ & (II-3) $14.34: 11.31: 2.64$ & $(\mathrm{III}-3) 11.31: 2.99: 8.84$ \\
$(\mathrm{I}-4) 2.99: 14.34: 5.23$ & (II-4) $14.34: 11.31: 2.20$ & $(\mathrm{III}-4) 11.31: 2.99: 7.85$
\end{tabular}

a "24A", "B", and “23B" respectively represent "alisol A 24-acetate", "alisol B", and "23-acetyl alisol B". 
Table 3 Characteristic values and the variance contribution rates

\begin{tabular}{llllll}
\hline & \multicolumn{2}{l}{ Initial characteristic value } & & & \multicolumn{2}{c}{ Extraction sums of squared loadings } \\
\cline { 2 - 3 } Component & Characteristic value & \% of variance & Cumulative\% & Total & \% of variance \\
\hline 1 & 3.500 & 87.490 & 87.490 & 3.500 & 87.490 \\
2 & 0.395 & 9.865 & 97.354 & & 87.490 \\
3 & 0.080 & 2.001 & 99.355 & \\
4 & 0.026 & 0.645 & 100.000 &
\end{tabular}

\section{Results}

\subsection{Effect of Alisma orientale extract on urine volume and concentrations of $\mathrm{Na}^{+}, \mathrm{K}^{+}$, and $\mathrm{Cl}^{-}$in the urine of water- loaded rats}

Compared with the blank group, the urine volume and concentration of $\mathrm{Na}^{+}, \mathrm{K}^{+}$and $\mathrm{Cl}^{-}$in the positive group of furosemide were significantly increased $(P<0.01)$, and the urine volume and concentration of $\mathrm{Na}^{+}, \mathrm{K}^{+}$and $\mathrm{Cl}^{-}$in the salt-made
Alisma orientale group from different origins were also significantly increased $(P<0.05$ or $P<0.01)$ (Table 4$)$, but there was no significant difference between the high and low doses from the same origin. Using urine volume as the main index, the urine ratio of rats in the high-dose salt-made Alisma orientale group from different producing areas followed the order Fujian $>$ Jiangxi $>$ Sichuan $>$ Hubei $>$ Guangxi $>$ Henan $>$ Hebei, while the urine ratio of rats in the low-dose salt-made Alisma orientale group from different producing areas was Fujian > Jiangxi >

Table 4 Determination of biochemical criteria in rats after being treated with Alisma orientale from different provinces ${ }^{a}$

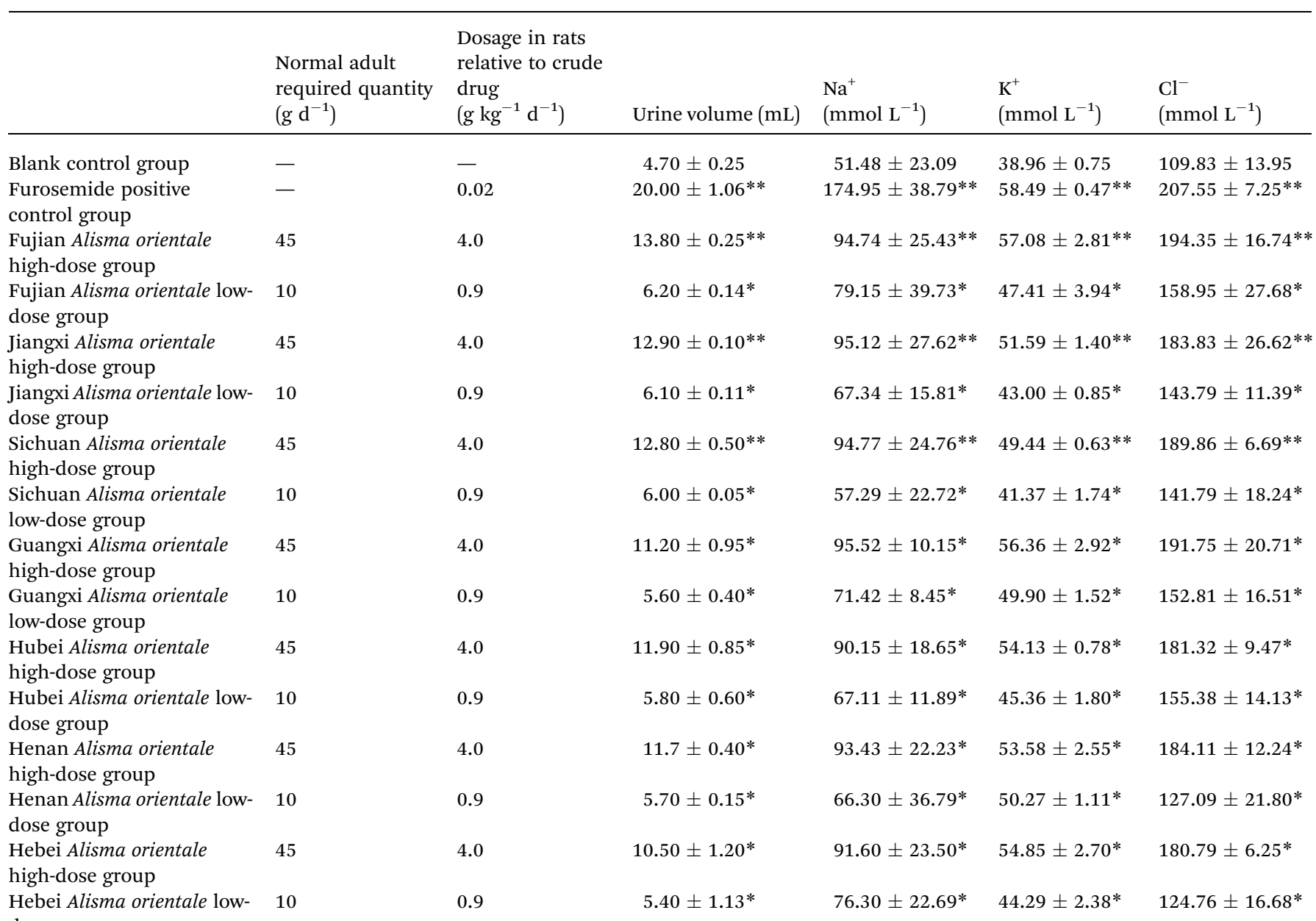

${ }^{a}$ Compared with the blank group, ${ }^{*} P<0.05,{ }^{*} P<0.01$. 

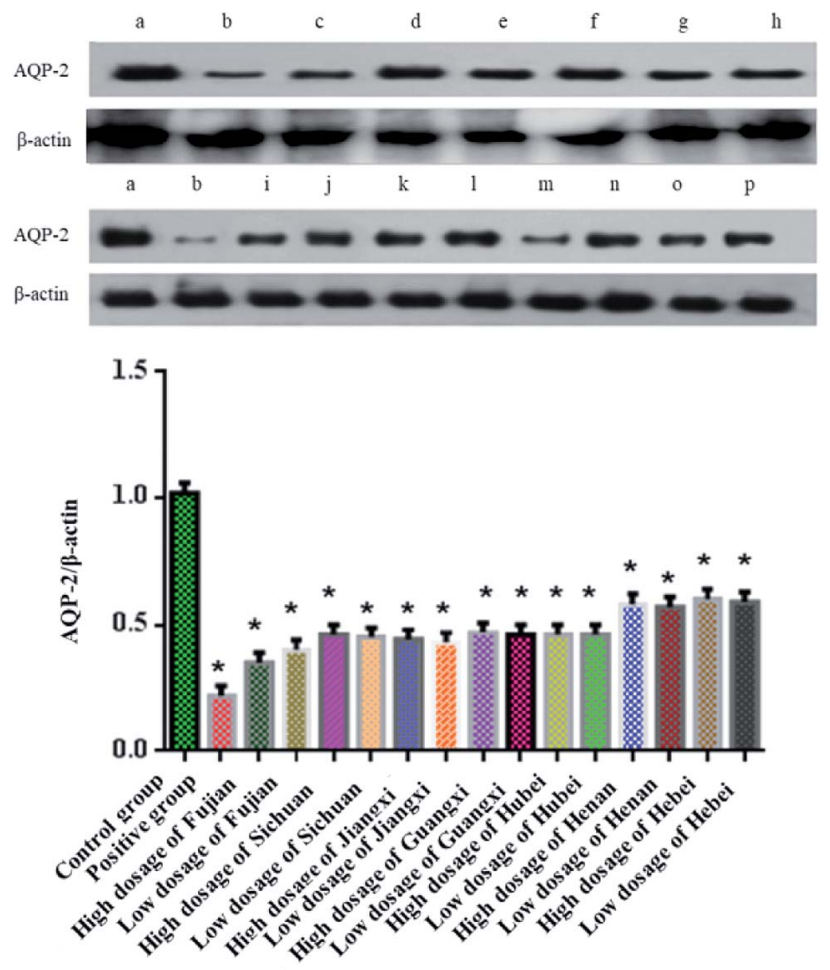

Fig. 1 The expression and quantitative analysis of AQP-2 in rats: (a) control group; (b) positive group; (c) high dosage of Fujian; (d) low dosage of Fujian; (e) high dosage of Sichuan; (f) low dosage of Sichuan; (g) high dosage of Jiangxi; (h) low dosage of Jiangxi; (i) high dosage of Guangxi; (j) low dosage of Guangxi; (k) high dosage of Hubei; (l) low dosage of Hubei; $(m)$ high dosage of Henan; $(n)$ low dosage of Henan; (o) high dosage of Hebei; and ( $p$ ) low dosage of Hebei. $* P<0.05$, versus control group.

Sichuan $>$ Hubei $>$ Guangxi $>$ Henan $>$ Hebei. The experimental results show that Alisma orientale in Fujian can obviously increase the urine output of water-loaded rats, and its diuretic effect is stronger than that of other producing areas.

Principal component analysis was performed to determine the urine volume and concentration of $\mathrm{Na}^{+}, \mathrm{K}^{+}$and $\mathrm{Cl}^{-}$in the urine from water-loaded rats treated with salt-made Alisma orientale from different origins. The results showed that the cumulative contribution rate of the first principal component is $87.49 \%$ (Table 3), and the first principal component is the urine volume through correlation principal component matrix analysis. Therefore, the urine volume of the principal component is taken as the main index for comparison of the drug efficacy between different origins in the later period.

The male SD water loaded rat model has been used in previous literature reports. ${ }^{21}$ In this experiment, the feasibility of the female SD rat water load model was investigated, it can be
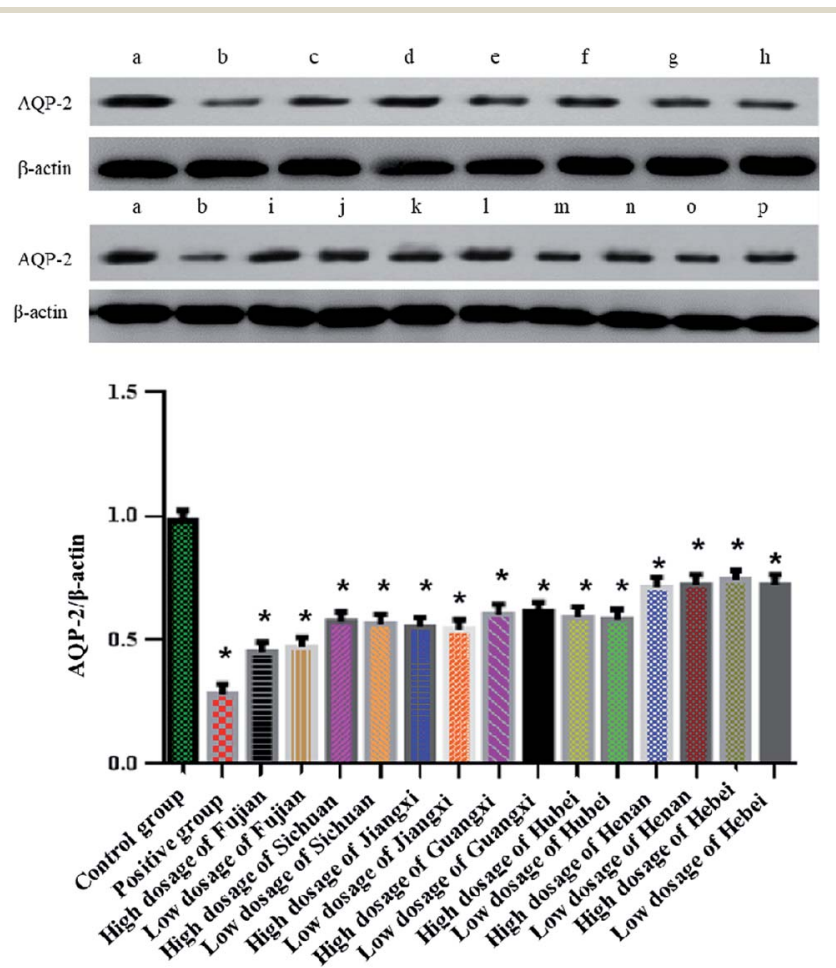

Fig. 2 The expression and quantitative analysis of AQP-2 in HK-2 cells. (a) Control group; (b) positive group; (c) high dosage of Fujian; (d) low dosage of Fujian; (e) high dosage of Sichuan; (f) low dosage of Sichuan; (g) high dosage of Jiangxi; (h) low dosage of Jiangxi; (i) high dosage of Guangxi; (j) low dosage of Guangxi; (k) high dosage of Hubei; (l) low dosage of Hubei; $(m)$ high dosage of Henan; $(n)$ low dosage of Henan; (o) high dosage of Hebei; and (p) low dosage of Hebei. $* P<0.05$, versus control group.

Table 5 Cell viability relating to different concentrations of Alisma orientale in HK-2 cells (mean $\pm \mathrm{SD}, n=6)^{a}$

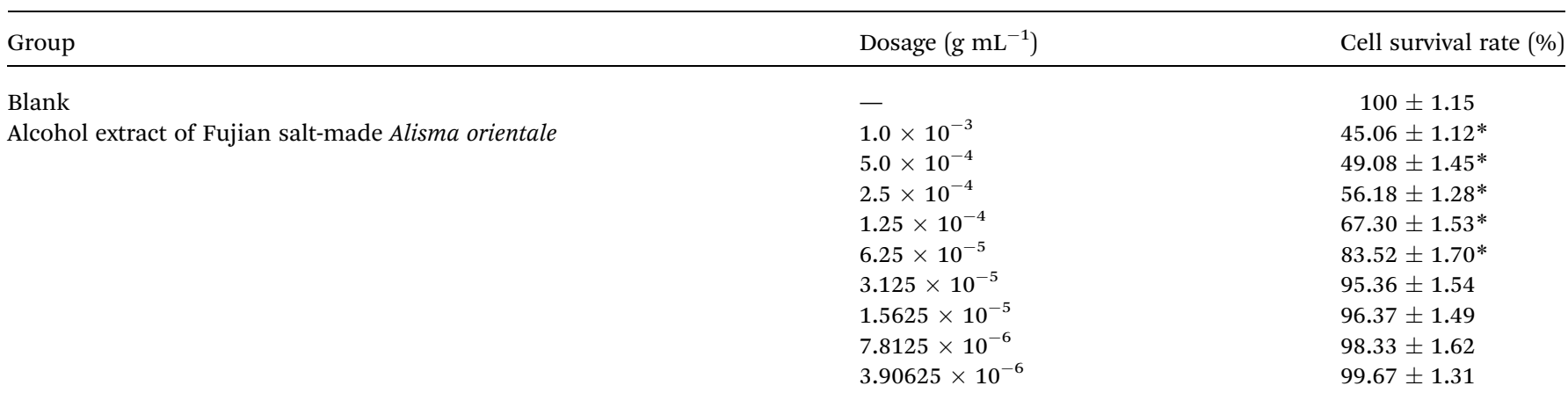

${ }^{a}$ Compared with the blank group, ${ }^{*} P<0.05$. 
seen that the female SD rat model has a good sensitivity and is consistent with the in vitro cell experiment results.

\subsection{Effect of Alisma orientale alcohol extract on AQP-2 in rat kidneys}

As shown in Fig. 1, compared with the blank group, the expression of AQP-2 in the renal medulla of rats in the furosemide group was significantly reduced $(P<0.05)$, while the expression of AQP-2 in the renal medulla of rats in the salt-made Alisma orientale group from different origins was also significantly reduced $(P<0.05)$, but there was no significant difference between the high and low doses from different origins. The expression comparison of AQP-2 in the kidney medulla of rats in the high dose group of salt-made Alisma orientale from different origins followed the order Fujian $<$ Jiangxi $<$ Sichuan $<$ Hubei $<$ Guangxi < Henan < Hebei, and the expression comparison of AQP-2 in the kidney medulla of rats in the low dose group was Fujian < Jiangxi $<$ Sichuan $<$ Hubei $<$ Guangxi $<$ Henan $<$ Hebei. The ability of Fujian Alisma orientale to reduce AQP-2 expression in rat renal medulla is higher than that of other producing areas, which further indicates that Fujian Alisma orientale has a stronger diuretic effect than that from other origins.

\subsection{Effect of salt-made Alisma orientale on HK-2 cell viability}

The MTT results show that the cell viability is $95.36 \pm 1.54 \%$ when the concentration of the extract of salt-made Alisma orientale is $3.125 \times 10^{-5} \mathrm{~g} \mathrm{~mL}^{-1}$. There was no significant difference in the cell viability in the control group, which indicates that these extracts have no obvious toxicity to the cells at this concentration. Therefore, $3.125 \times 10^{-5} \mathrm{~g} \mathrm{~mL}^{-1}$ and $1.5625 \times$ $10^{-5} \mathrm{~g} \mathrm{~mL}^{-1}$ were used for subsequent experimental studies (Table 5).

\subsection{Effect of Alisma orientale extract on AQP-2 expression in HK-2 cells}

As shown in Fig. 2, compared with the blank group, the expression of AQP-2 in HK-2 cells in the furosemide group was significantly reduced $(P<0.05)$, while the expression of AQP-2 in HK-2 cells in the salt-made Alisma orientale group from different origins was also significantly reduced $(P<0.05)$, but there was no significant difference between the high and low dose groups from different origins. The AQP-2 expression of HK-2 cells in the high-dose group of salt-made Alisma orientale from different origins followed the order Fujian $<$ Jiangxi $<$ Sichuan $<$ Hubei $<$ Guangxi $<$ Henan $<$ Hebei, while the AQP-2 expression of HK-2 cells in the low-dose group was Fujian $<$ Jiangxi $<$ Sichuan $<$
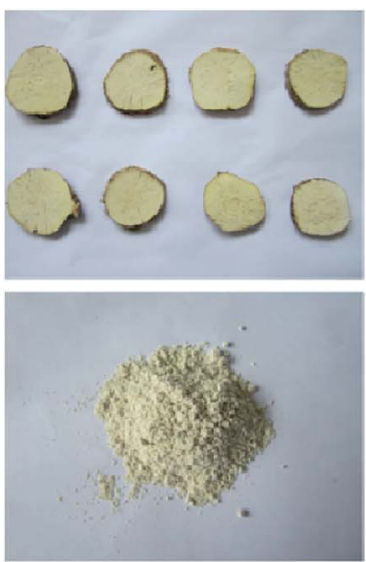

Fujian
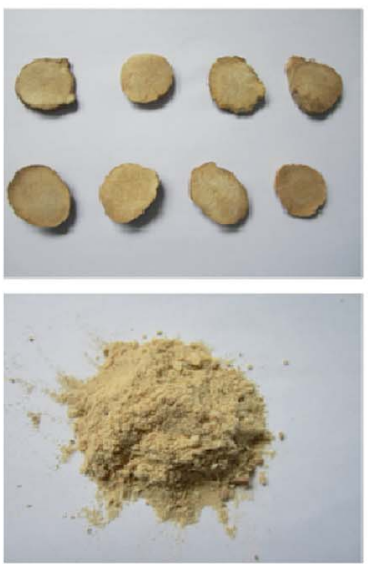

Hebei
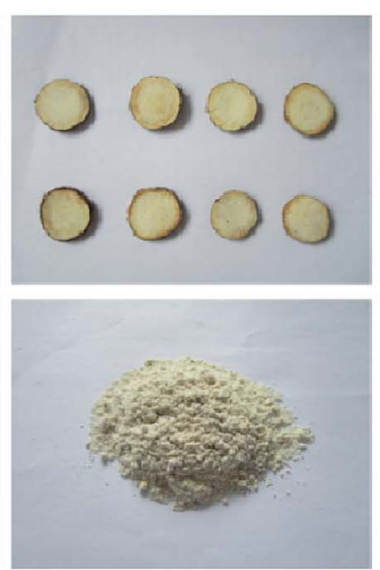

Sichuan
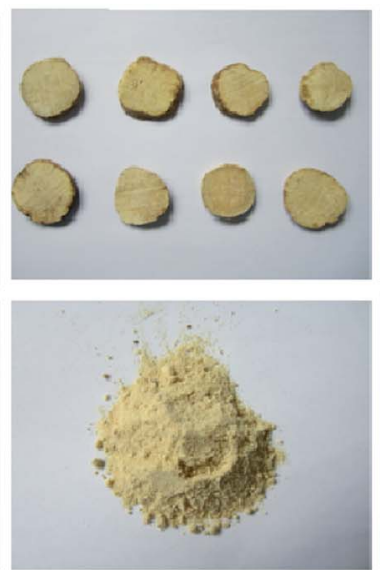

Hubei

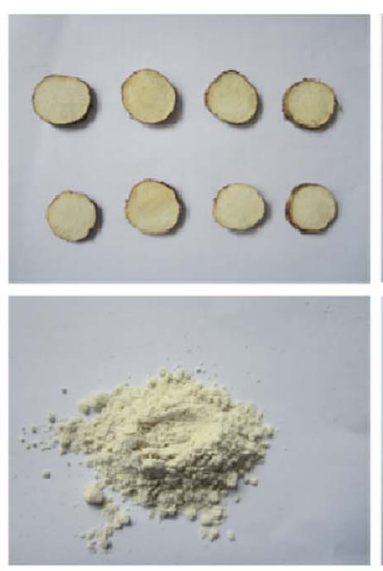

Jiangxi
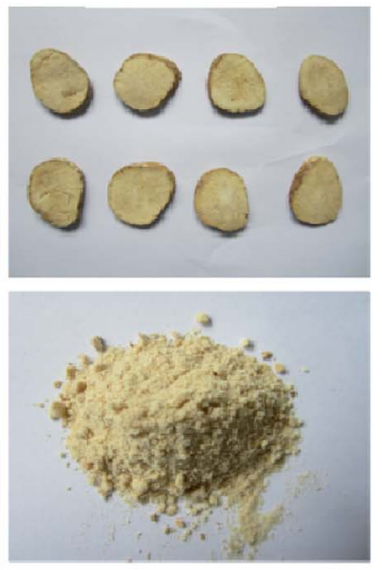

Henan

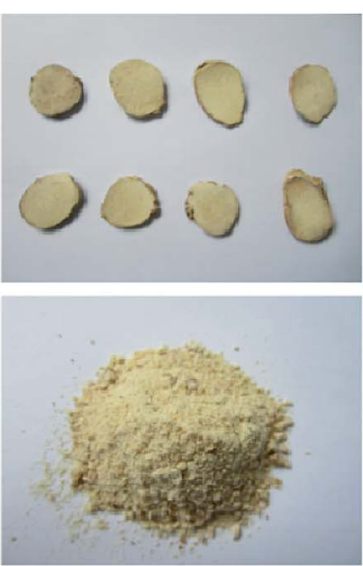

Guangxi

Fig. 3 Comparison of the characteristics of salted Alismatis Rhizoma from different places. 
Hubei < Guangxi < Henan < Hebei. The ability of Fujian Alisma orientale to reduce AQP-2 expression in HK-2 cells is higher than that in other producing areas. The results of the in vitro experiments also show that Fujian Alisma orientale has a stronger diuretic effect than those from other origins.

\subsection{Comparison of the description of salt-made Alisma orientale from different origins}

As can be seen from Fig. 3, the cross section of salt-made Alisma orientale from different origins is yellowish white, and the powder is powdery. The powder of salt-made Alisma orientale from Guangxi, Hebei, Hubei and Henan producing areas is yellowish, which may be related to the origin of salt-made Alisma orientale or a difference in the processing technology.

\subsection{Comparison of chromatograms of Alisma orientale from different origins}

HPLC was used to analyze the compounds of the salt-made Alisma orientale from different origins at $210 \mathrm{~nm}$ (Fig. 4). Peak area statistics and comparisons were carried out on the peaks of the 12 components in the methanol ultrasonic extract of Alisma orientale from different origins (Table 6).

\subsection{Principal component analysis of the components of salt- made Alisma orientale}

We analyzed the peak areas of 12 common components of saltmade Alisma orientale from nine different origins, we set 12 components as variables $\mathrm{X} 1-\mathrm{X} 12$ respectively, and established
Table 6 Peak area comparison of 12 components in salt-made Alisma orientale from different origins

\begin{tabular}{lrrlrrrr}
\hline Peak no. & Fujian & Jiangxi & Sichuan & Guangxi & Hubei & Hebei & Henan \\
\hline 1 & 34.1 & 184.8 & 144.9 & 31.7 & 317.7 & 346.8 & 222.0 \\
2 & 117.0 & 163.0 & 111.7 & 143.2 & 287.5 & 60.6 & 152.9 \\
3 & 9.4 & 213.8 & 24.2 & 761.3 & 496.2 & 780.2 & 965.3 \\
4 & 20.3 & 40.3 & 26.3 & 18.5 & 15.7 & 44.9 & 25.7 \\
5 & 357.3 & 121.4 & 777.1 & 1433.1 & 695.9 & 151.9 & 659.3 \\
6 & 687.6 & 160.5 & 516.8 & 58.4 & 921.0 & 1868.5 & 653.5 \\
7 & 189.4 & 111.8 & 516.8 & 321.5 & 107.5 & 112.1 & 75.2 \\
8 & 176.4 & 160.5 & 338.8 & 610.2 & 376.4 & 51.8 & 275.0 \\
9 & 70.9 & 105.9 & 190.4 & 438.6 & 219.1 & 37.8 & 225.1 \\
10 & 23.0 & 205.3 & 579.1 & 453.0 & 45.6 & 153.0 & 38.1 \\
11 & 89.2 & 295.6 & 154.4 & 183.0 & 143.9 & 252.7 & 133.2 \\
12 & 10.6 & 592.9 & 225.8 & 45.6 & 227.9 & 711.2 & 178.5 \\
& & & & & & &
\end{tabular}

chromatographic peak area data for the seven origins. The results showed that the cumulative contribution rate of the first principal component to the fourth principal component can reach $90.63 \%$, indicating that these four representative components are the main components of salt-made Alisma orientale. Finally, the peak numbers for the four components were determined to be 5, 8, 9 and 10 respectively, of which peaks 8, 9 and 10 are alisol A 24-acetate, alisol B and alisol B 23-acetate respectively (Tables 7 and 8).

The results of the principal component analysis showed that peaks 5, 8, 9 and 10 were the principal components of salt-made Alisma orientale prepared from different origins. Peaks 8, 9 and

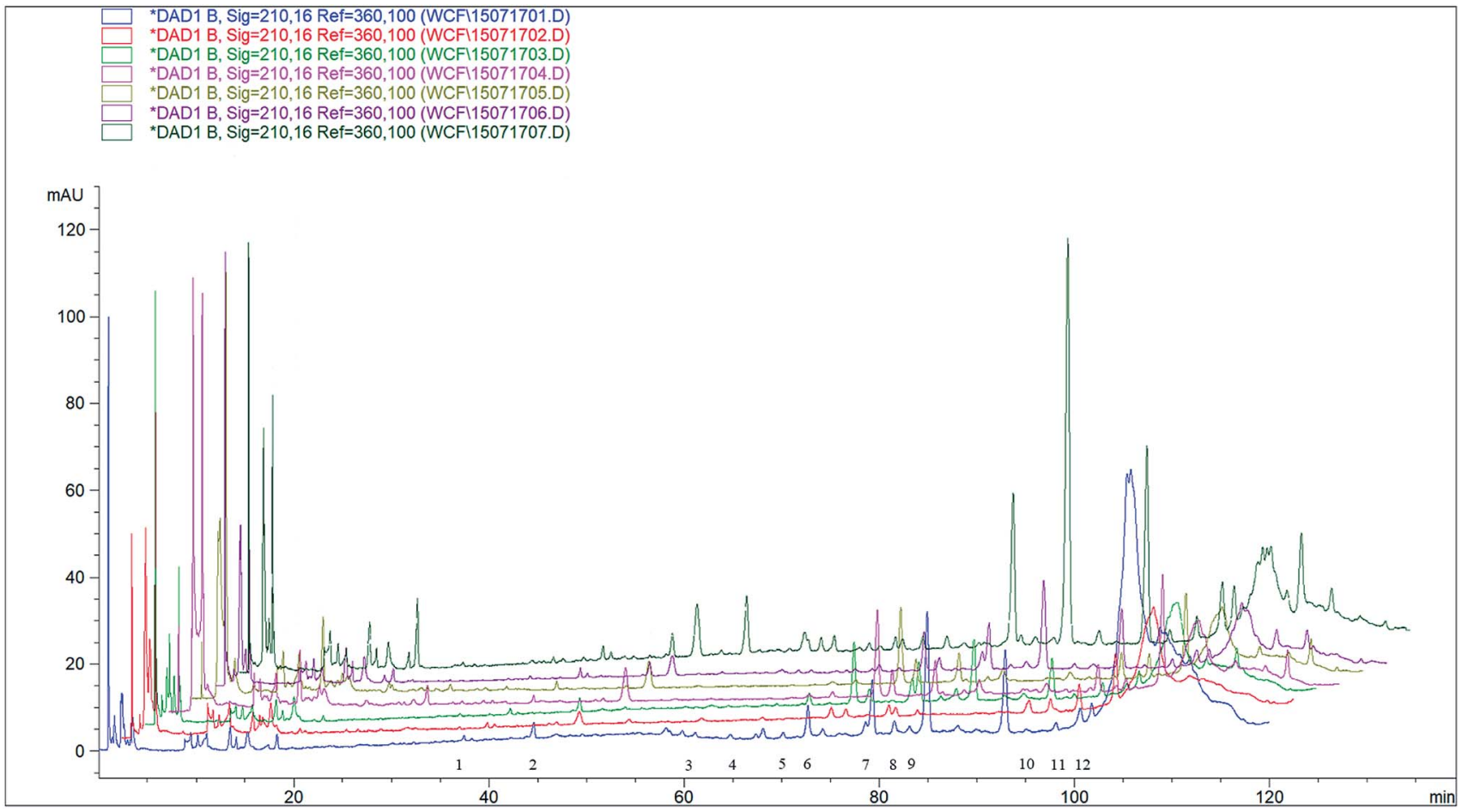

Fig. 4 HPLC chromatograms of salted Alismatis Rhizoma samples from different places; these are: Fujian Province, Jiangxi Province, Sichuan Province, Guangxi Province, Hubei Province, Hebei Province, and Henan Province, from front to back. 
Table 7 Characteristic values and the variance contribution rates

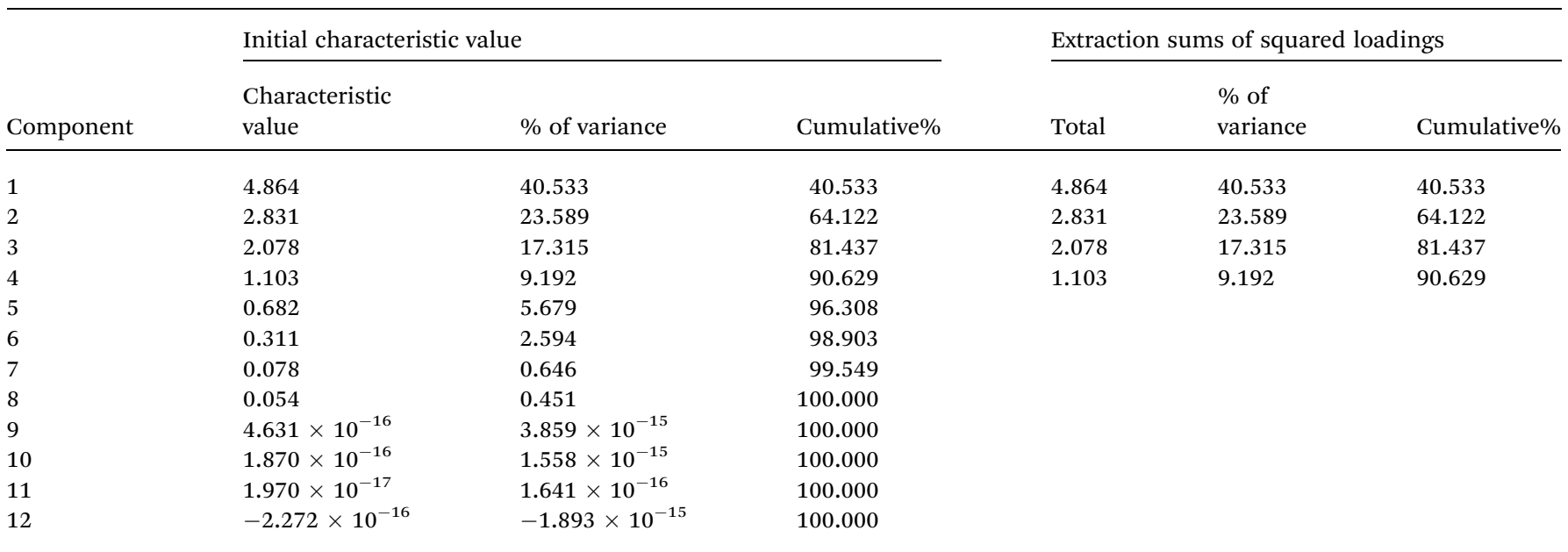

Table 8 Relative principal component matrix data

\begin{tabular}{|c|c|c|c|c|}
\hline \multirow[b]{2}{*}{ Component } & \multicolumn{4}{|c|}{ Principal component } \\
\hline & 1 & 2 & 3 & 4 \\
\hline $\mathrm{X} 1$ & -0.070 & 0.714 & 0.530 & -0.215 \\
\hline $\mathrm{X} 2$ & 0.237 & -0.405 & 0.568 & -0.603 \\
\hline $\mathrm{X} 3$ & 0.015 & -0.108 & 0.713 & 0.676 \\
\hline $\mathrm{X} 4$ & -0.718 & 0.481 & -0.199 & 0.236 \\
\hline $\mathrm{X} 5$ & 0.955 & -0.071 & 0.132 & 0.206 \\
\hline $\mathrm{X} 6$ & -0.760 & 0.068 & 0.140 & 0.255 \\
\hline $\mathrm{X} 7$ & 0.655 & 0.216 & -0.655 & 0.009 \\
\hline $\mathrm{X} 8$ & 0.973 & -0.121 & 0.156 & 0.045 \\
\hline X9 & 0.932 & -0.061 & 0.281 & 0.202 \\
\hline $\mathrm{X} 10$ & 0.695 & 0.451 & -0.488 & 0.114 \\
\hline $\mathrm{X} 11$ & 0.204 & 0.915 & 0.164 & -0.095 \\
\hline $\mathrm{X} 12$ & 0.163 & 0.894 & 0.305 & -0.092 \\
\hline
\end{tabular}

10 are alisol A 24-acetate, alisol B and alisol B 23-acetate, respectively. Therefore, the three components are representative components of salt-made Alisma orientale. According to the pharmacodynamic results mentioned above, the peak area ratio of alisol A 24-acetate, alisol B and alisol B 23-acetate is $1: 0.40: 0.13$ which represents the best effect of the drug. This ratio is the characteristic feature of geoherb Alisma orientale and enables the excellent "diuresis and diffusing dampness" performance (Table 9).

\subsection{Effects of different structural optimizations of terpenoids on the expression of AQP-2 and Kim-1 in HK-2 cells}

From the experimental results described in the previous section, it can be seen that the diuretic effect of salt-made Alisma orientale is related to a significant reduction in the expression of the AQP-2 protein, and the nephrotoxicity is manifested by a significant enhancement in the Kim-1 protein expression. As shown in Fig. 5 and Table 8, compared with the blank group, when the component structure of alisol A 24-acetate: alisol B:alisol B 23-acetate is $2.99: 14.34: 11.43$ to $2.99: 14.34: 6.01$ (i.e. $\mathrm{I}-1-\mathrm{I}-3$ ), the expression of the AQP-2 protein is significantly reduced $(P<0.05)$, and at the same time, the level of the Kim-1 protein is not significantly different from the blank group when I-2-I-4 $(P>0.05)$. To summarize, the structural ratios of alisol A 24-acetate: alisol B : alisol B 23acetate are $2.99: 14.34: 8.08$ and $2.99: 14.34: 6.01$, and the components are safe and effective. With the decrease in the $24 \mathrm{~A}$ structural ratio, the expression of the AQP-2 protein decreased gradually, and the expression of the Kim-1 protein also decreased gradually. When alisol B : alisol B 23-acetate : alisol A 24-acetate is $14.34: 11.31: 5.38$ (i.e. II-2), the expression of the

Table 9 Composition and structural characteristics of salt-made Alisma orientale

\begin{tabular}{llcrl}
\hline & \multicolumn{2}{c}{ Peak area } & & \multicolumn{1}{c}{$\begin{array}{c}\text { Structural characteristics } \\
\text { (peak area ratio) }\end{array}$} \\
\cline { 2 - 3 } Origin & Alisol A 24-acetate & Alisol B & Alisol B 23-acetate & $1: 0.40: 0.13$ \\
Fujian & 176.4 & 70.9 & 23.0 & $1: 0.66: 1.28$ \\
Jiangxi & 160.5 & 105.9 & 205.3 & $1: 0.56: 1.71$ \\
Sichuan & 338.8 & 190.4 & 579.1 & $1: 0.72: 0.74$ \\
Guangxi & 610.2 & 438.6 & 453.0 & $1: 0.58: 0.12$ \\
Hubei & 376.4 & 219.1 & 45.6 & $1: 0.73: 2.95$ \\
Hebei & 51.8 & 37.7 & 153.0 & $1: 0.82: 0.14$
\end{tabular}


(A)
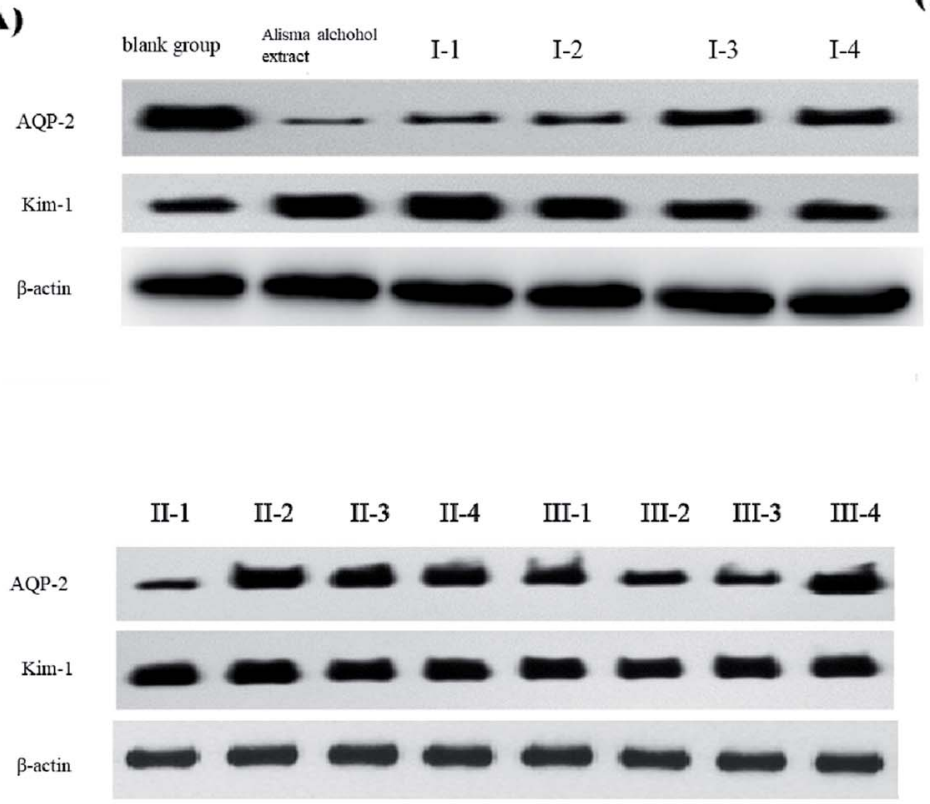

(B)
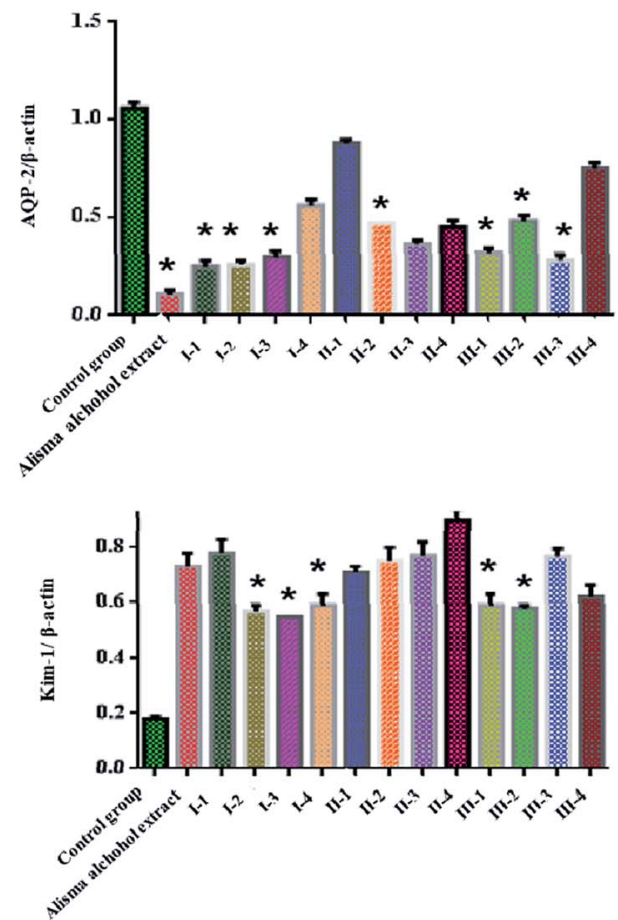

Fig. 5 The protein expressions of AQP-2 and Kim-1 were determined using western blot. *: $P<0.05$, compared with the control group.

terpene component AQP-2 protein decreased significantly $(P<$ 0.05 ) and its toxicity was relatively low compared with the blank group. Compared with the blank group, when the structural ratio of alisol B 23-acetate: alisol A 24-acetate: alisol B is $11.31: 2.99: 14.25$ to $11.31: 2.99: 8.84$ (i.e. III-1-III-3), the AQP-2 protein expression is significantly reduced $(P<0.05)$, but when the structural ratio of them is $11.31: 2.99: 14.25$, it is revealed that the HK-2 cells are toxic $(P>0.05)$. Therefore, when the structural ratios of alisol B 23-acetate: alisol A 24-acetate : alisol B are $11.31: 2.99: 8.84$ and $11.31: 2.99: 9.06$, the components are safe and effective. To summarize, the high efficiency and low toxicity of Alisma orientale were fully analyzed, and the terpenoid components of Alisma orientale were preliminarily confirmed as alisol A 24-acetate: alisol $\mathrm{B}$ : alisol B 23-acetate and their structural ratio is $5.38: 14.34: 11.31$.

\section{Discussion}

It is very common that the same kind of traditional Chinese medicine produced in different areas shows differences in the quality of medicinal materials, owing to the significant difference in the climatic conditions and soil environment in China. Therefore, an accurate quality evaluation of traditional Chinese medicine from different regions is the key to preventing and treating diseases. In order to explore the intrinsic reasons for the superiority of geoherb salt-made Alisma orientale, a pharmacodynamic experiment was carried out to verify the superiority of Fujian Alisma. HPLC and principal component analysis were carried out and they revealed the structural composition of the components of salt-made Alisma orientale from the Fujian Province. Finally, in order to study the toxicity of Alisma orientale, an experiment was performed to determine the structural optimization and showed the safe and effective range of the ratio of components in Alisma orientale.

"Diuresis and diffusing dampness" have been regarded as the traditional effect of Alisma orientale. Aquaporin is the target molecule for diuretic traditional Chinese medicine to exerts its efficacy. AQP-2 is the main target molecule of the antidiuretic hormone for the regulation of water permeability of the collector tube, and it plays an important role in adjusting urine concentration. $^{22}$ Diuretic effects are closely related to the excretion of $\mathrm{Na}^{+}, \mathrm{K}^{+}$and $\mathrm{Cl}^{-}$in the body and the regulation of aquaporins. ${ }^{23,24}$ Therefore, the urinary $\mathrm{Na}^{+}, \mathrm{K}^{+}$and $\mathrm{Cl}^{-}$levels and the expression of AQP-2 were used to study the efficacy of diuresis and diffusing dampness. In this paper, the diuretic effects of Alisma orientale were investigated in vivo and in vitro, and the efficacy of salted Alisma orientale from seven different producing areas was compared. The results showed that the effect of Alisma orientale was mainly the increase in urine volume and the level of $\mathrm{Na}^{+}, \mathrm{K}^{+}$and $\mathrm{Cl}^{-}$in urine, and it is also related to the regulation of AQP-2 expression. By analyzing the diuretic effect of Alisma orientale from different producing areas, we found that the effect of Alisma orientale from Fujian on increasing urine volume and reducing AQP-2 expression was the most significant, which suggests that Fujian Salted Alisma orientale has a better "diuresis and diffusing dampness" effect than those from other producing areas, which can be used as a preliminary indication of its "superiority". 
In our research, we evaluated the nephrotoxicity of Alisma orientale. Kim-1, a type I transmembrane protein, is highly expressed in the proximal tubule cells after ischemia and renal toxicity injury, but is rarely expressed in normal renal tissue. Previous studies have shown that Kim-1 is a highly sensitive and specific biomarker of renal tubular toxicity. ${ }^{25}$ Traditional Chinese medicine as a whole consists of a certain ratio of components and its efficacy can be exerted through the synergistic action of each component. Toxicity also has a regulatory mode when the ratio of components is beyond a certain balance range. Therefore, the structural optimization of the components of Alisma orientale was determined in order to obtain the safe ratio range of the components. The results showed that when the ratio of alisol A 24-acetate : alisol B : alisol B 23acetate is $5.38: 14.34: 11.31$, we can ensure the efficacy of Alisma orientale and reduce the nephrotoxicity caused by it.

The multi-target and multi-path action mode of traditional Chinese medicine suggests that the effectiveness of traditional Chinese medicine depends not on the role of a certain component, but on the result of the synergy of multiple components within/between components. Principal component analysis is used to convert multiple indicators into a few comprehensive indicators, that is, the main component, and the use of comprehensive indicators to analyze problems is widely used in the field of traditional Chinese medicine. Principal component analysis was carried out and three main components were obtained, alisol A 24-acetate, alisol B and alisol B 23-acetate, and the peak area ratio of the main three components in Fujian Alisma orientale was found to be $1: 0.4: 1.3$, which is close to the ratio of the three components after optimization with better efficacy and no obvious nephrotoxicity. Judging from the three main component peak areas of salt-made Alisma orientale in various producing areas, Fujian salt-made Alisma orientale did not show any advantages in terms of the contents of the individual components. In contrast, the peaks area of these three components in Fujian salt-formed Alisma orientale are much smaller than that of several other producing areas, which further indicates that studying the quality evaluation of traditional Chinese medicine by determining the contents of several components is unreliable. There is a synergy between the three main components of Alisma orientale. This synergy is not a simple superposition of components, but a difference in the contribution of each component to the overall drug effect. According to the pharmacodynamic experiments, we can see that when the component ratio of the different areas producing Alisma orientale approaches the optimal ratio, the efficacy was improved.

It is worth noting that there was no significant difference between the high and low doses from different origins. This suggests that the relationship between the Alisma orientale dose and diuretic efficacy may not be linear. A similar phenomenon can be seen in other studies and the results suggest that Alisma orientale may contain both diuretic and antidiuretic components. The antidiuretic effect of Alisma orientale might be exerted by promoting the sodium-chloride co-transporter in the distal tubule. ${ }^{26,27}$ In addition, many kinds of traditional Chinese medicine have been found to have a bidirectional regulation effect through different targets. ${ }^{28}$ Alisma orientale may also have this effect. The relationship between the dose of Alisma orientale and the diuretic efficacy requires further research.

\section{Conclusions}

The "Structural Composition of Components Theory" proposed by our research group clearly indicates that the proportional relationships between components ${ }^{29}$ are the material basis of traditional Chinese medicine. This study found that Fujian saltmade Alisma orientale exhibits the best diuretic effect and the optimal structural composition of the components of salt-made Alisma orientale has a ratio of alisol A 24 -acetate, alisol B, and alisol B 23-acetate of $1: 0.4: 1.3$. The quality evaluation of traditional Chinese medicine based on the "Structural Composition of multi-Components Theory" can effectively avoid differences in the levels of components caused by the environment, and lays the foundation for the quality evaluation of salt-made Alisma orientale and other herb slices.

\section{Conflicts of interest}

There are no conflicts to declare.

\section{Acknowledgements}

This research was financially supported by the National Natural Science Foundation Committee of P. R. China (No. 81603382, 81703775), "Double First-Class" University project of China Pharmaceutical University (CPU2018GF07, CPU2018PZQ19), and Key research projects on modernization of traditional Chinese medicine (2018YFC1706900).

\section{References}

1 G. Yu, Z. Luo, W. Wang, Y. Li, Y. Zhou and Y. Shi, Front. Pharmacol., 2019, 10, 799.

2 M. S. Tsang, P. C. Shaw, I. M. Chu, L. Cheng, E. C. Wong, D. T. Lau, C. W. Lam and C. K. Wong, Molecules, 2019, 24, 2880 .

3 W. K. Zheng, L. Zhang and S. J. Zan, Zhongguo Zhongyao Zazhi, 2019, 44, 624-628.

4 P. Zhang, M. H. Li, Y. Shi, X. L. Cheng, H. Yan, W. Liu, F. Wei and S. C. Ma, Zhongguo Zhongyao Zazhi, 2018, 43, 4198-4202.

5 L. X. Zhu, J. Xu, Y. Wu, L. F. Su, K. Y. C. Lam, L. Ching, E. R. Qi, X. P. Dong, H. B. Chen, Y. D. Liu and Z. Z. Zhao, J. Food Drug Anal., 2019, 27, 766-777.

6 Y. X. Li, X. H. Gong, M. C. Liu, C. Peng, P. Li and Y. T. Wang, J. Evidence-Based Complementary Altern. Med., 2017, 2017, 6238464.

7 Chinese Pharmacopoeia Commission of China, Ch. P., Beijing, 2015, p. 229.

8 A. C. Zhou, C. F. Zhang and M. Zhang, Chin. J. Nat. Med., 2008, 6, 109-111.

9 X. Y. Hu, Y. Q. Guo, W. Y. Gao and T. J. Zhang, Chin. Chem. Lett., 2008, 19, 438-440. 
10 X. Liu, S. L. Li and H. X. Xu, J. Mass Spectrom., 2010, 24, 15141522.

11 X. Y. Hu, Y. Q. Guo and H. X. Chen, Sep. Purif. Technol., 2008, 10, 481-484.

12 Y. L. Feng, H. Chen and R. C. Lin, J. Ethnopharmacol., 2014, 154, 386-390.

13 D. Q. Chen, Y. L. Feng and R. C. Lin, J. Ethnopharmacol., 2014, 157, 114-118.

14 T. Tian, H. Chen and Y. Y. Zhao, J. Ethnopharmacol., 2014, 158, 373-387.

15 Z. Shu, J. Pu, L. Chen, Y. Zhang, K. Rahman, L. Qin and C. Zheng, Am. J. Chin. Med., 2016, 44, 227-251.

16 L. L. Zhang, W. Xu, Y. L. Xu, X. Chen, M. Huang and J. J. Lu, Ann. N. Y. Acad. Sci., 2017, 1401, 90-101.

17 H. S. Lee, I. H. Hwang and J. A. Kim, Bull. Korean Chem. Soc., 2011, 32, 697-700.

18 W. X. Zhao, N. Cui, H. Q. Jiang, X. M. Ji, X. C. Han, B. B. Han, T. Wang and S. J. Wang, J. Evidence-Based Complementary Altern. Med., 2017, 2017, 4946031.

19 Y. Y. Zhao, R. M. Xie, X. Chao, Y. Zhang, R. C. Lin and W. J. Sun, J. Ethnopharmacol., 2009, 126, 184-187.

20 P. L. Jørgensen, J. Petersen and W. D Rees, Biochim. Biophys. Acta, Biomembr., 1984, 775, 105-110.
21 X. Zhang, X. Y. Li, N. Lin, W. L. Zhao, X. Q. Huang, Y. Chen, M. Q. Huang, W. Xu and S. S. Wu, Molecules, 2017, 22, 1459.

22 J. He, L. Zeng, R. Wei, G. Zhong, Y. Zhu, T. Xu and L. Yang, J. Ethnopharmacol., 2019, 231, 446-452.

23 E. Moreno, J. A. Gayosso, J. R. Montejano, G. Almaguer, N. Vázquez, C. Cruz, A. Mercado, N. A. Bobadilla, G. Gamba, A. Sierra and V. Ramírez, Am. J. Physiol.: Renal Physiol., 2017, 314, F240-F250.

24 L. Santucci, G. Candiano, M. Bruschi, M. Bodria, C. Murtas, A. Petretto and G. M. Ghiggeri, Am. J. Nephrol., 2013, 26, 610616.

25 L. Yang, C. R. Brooks, S. Xiao, V. Sabbisetti, M. Y. Yeung, L. L. Hsiao, T. Ichimura, V. Kuchroo and J. V. Bonventre, J. Clin. Invest., 2015, 125(4), 1620-1636.

26 D. Q. Chen, Y. L. Feng, T. Tian, H. Chen, L. Yin, Y. Y. Zhao and R. C. Lin, J. Ethnopharmacol., 2014, 157, 114-118.

27 Y. L. Feng, H. Chen, T. Tian, D. Q. Chen, Y. Y. Zhao and R. C. Lin, J. Ethnopharmacol., 2014, 154(2), 386-390.

28 H. J. Wang, J. J. Wu, Q. Xue, J. F. Zhang and X. Y. Xu, China J. Chin. Mater. Med., 2017, 11, 2200-2207.

29 X. B. Jia, B. Yang, L. Feng, X. H. Shi, H. Wang and L. G. Liu, Acta Pharmacol. Sin., 2018, 53, 1943-1953. 